\title{
Sarcopenia: assessment of disease burden and strategies to improve outcomes
}

This article was published in the following Dove Press journal:

Clinical Interventions in Aging

\author{
Ilaria Liguori' \\ Gennaro Russo' \\ Luisa Aran' \\ Giulia Bulli' \\ Francesco Curcio' \\ David Della-Morte ${ }^{2,3}$ \\ Gaetano Gargiulo 4 \\ Gianluca Testa ${ }^{1,5}$ \\ Francesco Cacciatore ${ }^{1,6}$ \\ Domenico Bonaduce' \\ Pasquale Abete' \\ 'Department of Translational \\ Medical Sciences, University of \\ Naples "Federico II", Naples, Italy; \\ ${ }^{2}$ Department of Systems Medicine, \\ University of Rome Tor Vergata, Rome, \\ Italy; ${ }^{3}$ Department of Human Sciences \\ and Quality of Life Promotion, San \\ Raffaele Roma Open University, Rome, \\ Italy; ${ }^{4}$ Division of Internal Medicine, \\ AOU San Giovanni di Dio e Ruggi di \\ Aragona, Salerno, Italy; ${ }^{5}$ Department \\ of Medicine and Health Sciences, \\ University of Molise, Campobasso, \\ Italy; ${ }^{6}$ Azienda Ospedaliera dei \\ Colli, Monaldi Hospital, Heart \\ Transplantation Unit, Naples, Italy
}

Correspondence: Pasquale Abete Department of Translational Medical Sciences, University of Naples "Federico II", Via S. Pansini, 5, 8013 I Naples, Italy

Tel +39817462270

Fax +39817462339

Email p.abete@unina.it

\begin{abstract}
Life expectancy is increasing worldwide, with a resultant increase in the elderly population. Aging is characterized by the progressive loss of skeletal muscle mass and strength a phenomenon called sarcopenia. Sarcopenia has a complex multifactorial pathogenesis, which involves not only age-related changes in neuromuscular function, muscle protein turnover, and hormone levels and sensitivity, but also a chronic pro-inflammatory state, oxidative stress, and behavioral factors - in particular, nutritional status and degree of physical activity. According to the operational definition by the European Working Group on Sarcopenia in Older People (EWGSOP), the diagnosis of sarcopenia requires the presence of both low muscle mass and low muscle function, which can be defined by low muscle strength or low physical performance. Moreover, biomarkers of sarcopenia have been identified for its early detection and for a detailed identification of the main pathophysiological mechanisms involved in its development. Because sarcopenia is associated with important adverse health outcomes, such as frailty, hospitalization, and mortality, several therapeutic strategies have been identified that involve exercise training, nutritional supplementation, hormonal therapies, and novel strategies and are still under investigation. At the present time, only physical exercise has showed a positive effect in managing and preventing sarcopenia and its adverse health outcomes. Thus, further well-designed and well-conducted studies on sarcopenia are needed.
\end{abstract}

Keywords: sarcopenia, elderly, assessment, therapy

\section{Definition of sarcopenia}

The overall life expectancy of the human population is dramatically increasing worldwide, not only because of declining fertility and increasing longevity, ${ }^{1}$ but also as a result of improved life conditions and the availability of innovative treatments, especially for infectious and cardiovascular diseases (CVDs). ${ }^{2}$ Particularly in the USA, the population over ages 65 and 85 are expected to increase in 2030 by a percentage of $147 \%$ and $389 \%$, respectively. ${ }^{3}$

Aging is associated with a progressive loss of tissue and organ function over time. ${ }^{4}$ As the human body ages, the skeletal muscle mass declines annually by $\sim 0.1 \%-0.5 \%$ starting from age 30 , with a dramatic acceleration post age 65 ; this gradual decrease in muscle mass is accompanied by a simultaneous reduction of strength. ${ }^{5}$ This age-related loss of muscle mass and strength is often referred to as "sarcopenia". ${ }^{6}$ Although the term "sarcopenia" (from Greek sarx: flesh and penia: deficiency) was introduced for the first time by Rosenberg, ${ }^{7}$ there is still no widely accepted definition of this condition. However, a practical clinical definition was developed in 2009-2010 by the European Working Group on Sarcopenia in Older People (EWGSOP) that defined sarcopenia as "a syndrome characterized by progressive and generalized loss of skeletal muscle mass and strength with a risk of adverse outcomes such as physical disability, (c)
hereby accept the Terms. Non-commercial uses of the work are permitted without any further permission from Dove Medical Press Limited, provided the work is properly attributed. For permission for commercial use of this work, please see paragraphs 4.2 and 5 of our Terms (https://www.dovepress.com/terms.php). 
poor quality of life and death". ${ }^{8}$ In fact, sarcopenia is related to a series of significant economic and social implications, including disability, hospitalization, and death, ${ }^{9}$ evidenced the fact that, in 2000, the direct cost attributed to sarcopenia was $1.5 \%$ of the total health care expenditure. ${ }^{2}$ Thus, the aim of this review is to summarize the evidences currently available about the pathogenesis, appropriate assessment, and the possible treatment strategies of sarcopenia.

\section{Pathogenesis of sarcopenia}

Sarcopenia is considered a complex geriatric syndrome because of its multifactorial pathogenesis. ${ }^{5}$ Several agerelated factors, such as neuromuscular degeneration, changes in muscle protein turnover, changes in hormone levels and sensitivity, chronic inflammation, oxidative stress, and behavior/lifestyle factors, are involved in the development of sarcopenia. ${ }^{10}$

\section{Neuromuscular degeneration}

One of the most investigated mechanisms involved in the pathogenesis of sarcopenia is neuromuscular degeneration, characterized by the atrophy of muscle fibers (especially type II fibers [fast]), decreased number of alpha motor units from the spinal cord, and accumulation of fat within muscle. ${ }^{11}$ In particular, aging is characterized by a progressive and probably irreversible neuron loss, which also involves motor neurons, with the consequent denervation of muscle fibers that fail in contributing to muscle contraction. ${ }^{12}$ To counteract the functional decline deriving from this process, de-enervated fibers express proteins and produce chemotactic signals that stimulate the re-innervation by the expansion of residual motor units. ${ }^{13}$ However, with aging, this dynamic de-enervation-re-innervation cycle starts failing ${ }^{14}$ and there is considerable atrophy of muscle fibers, mainly type II (fast and glycolytic), with a gradual decrease in size/volume accompanied by a replacement of muscle by fat and connective tissue. ${ }^{15}$ This phenomenon may explain why the effects of sarcopenia are generally more evident in anti-gravitary muscle groups of the lower limbs $(\sim 15 \%)$ than in the upper limbs $(\sim 10 \%)$ for both men and women. ${ }^{16}$ Moreover, age-related neuromuscular dysfunction is characterized by an impairment of Schwann cells, such as increased fragmentation, damage, or denervation, which may also contribute to ineffective re-innervation of muscle fibers. ${ }^{11}$ In greater detail, because neuromuscular junctions (NMJs) - the synaptic interface between a branch of a motor neuron and muscle cells - are involved in the transduction of muscle action potentials, they play a key role in the neuromuscular impairment that occurs with aging and their dysfunction seems to be largely associated with sarcopenia, ${ }^{11}$ leading to neuromuscular fatigue during exercise and an age-related reduced response to physical training. ${ }^{17}$ The NMJ is composed of three elements: presynaptic (motor nerve terminal), intrasynaptic (synaptic basal lamina), and postsynaptic (muscle fiber and muscle membrane) components. ${ }^{18}$ With aging, both the nerve terminal area and the number of postsynaptic folds are reduced, thereby leading to a functional impairment in the postsynaptic response of the NMJ. ${ }^{11}$ The mitochondria in NMJs are numerically reduced and tend to show signs of degeneration (ie, cristae disruption, swelling, formation of megamitochondria due to multiple fusions between adjacent mitochondria), ${ }^{19}$ leading to high levels of oxidative damage, decreased number of synaptic vesicles, and lower quantities of neurotransmitter release during depolarization. ${ }^{11}$

\section{Changes in muscle protein turnover}

Muscle mass is determined by the balance between protein synthesis and breakdown. ${ }^{2}$ The best-defined anabolic pathway leading to protein synthesis in muscle involves the serine/ threonine kinase Akt/protein kinase B (PKB), the mammalian target of rapamycin (mTOR), hormones such as insulin-like growth factor-1 (IGF-1) and insulin, as well as branched-chain amino acids (eg, leucine, valine, isoleucine) and exercise. ${ }^{20}$ In particular, the kinase mTOR interacts with several proteins to form two complexes: mTOR complex 1 (mTORC1; containing raptor) and mTOR complex 2 (mTORC2; containing rictor). ${ }^{21} \mathrm{mTORC} 1$ has a major role in mediating the effect of mTOR on protein synthesis. ${ }^{22}$ Although the mechanism of control of protein synthesis by mTOR is not completely understood, mTORC1 seems to promote protein synthesis by inhibiting the eukaryotic translation initiation factor 4E-binding protein 1 (4E-BP1) and activating p70 S6 kinase $1\left(\mathrm{p} 70^{\mathrm{s} 6 \mathrm{k}}\right) .{ }^{21} \mathrm{mTOR}$ can be activated by several stimuli (ie, IGF-1, insulin, amino acids, and exercise). ${ }^{23}$ In further detail, when IGF-1 and insulin bind to tyrosine kinase receptors, they induce the phosphorylation of the receptor itself and of several substrates, thus leading to the activation of mTOR through the activation of phosphatidylinositol 3-kinase (PI3K) and its downstream effector Akt/PKB. ${ }^{24}$ At the same time, Akt/PKB can promote the suppression of apoptosis and protein degradation in skeletal muscle through the phosphorylation of FOXO1 transcription factors, thereby inhibiting the expression of the E3 ubiquitin ligases atrogin-1 and muscle RING-finger protein-1 (MuRF-1). ${ }^{25}$ The mechanisms by which branched-chain amino acids - which 
are particularly effective anabolic agents - stimulate mTOR is not fully understood, but they do not require activation of PKB. ${ }^{26}$ Several hypotheses have been proposed to explain this phenomenon. Amino acids could directly activate mTOR, or indirectly activate it by stimulating a protein kinase different from PKB. Moreover, they could inhibit a protein phosphatase (ie, protein phosphatase $2 \mathrm{~A}$ ) or interact with proteins associated with $\mathrm{mTOR}$ (ie, raptor). ${ }^{23}$ Further, acute resistance exercise is known to increase skeletal muscle protein synthesis by directly activating mTOR or indirectly activating it via Akt/PKB. ${ }^{27}$ Few studies evaluating age-related changes of protein synthesis pathways in humans have been conducted; however, taken together, they show an aging-related decline in Akt/PKB-mTOR signaling and protein synthesis that contributes to sarcopenia. ${ }^{28}$ The breakdown of muscle protein involves the activation of the ubiquitin proteasome pathway by transforming growth factor $\beta$ (TGF $\beta$ ) and myostatin - a member of the TGF $\beta$ superfamily of cytokines. ${ }^{2}$ Both myostatin and TGF- $\beta$ are potent inducers of muscle atrophy. They are held in an inactive form in the muscle extracellular matrix and, when activated, stimulate Smad2/3 and TAK1/p38 MAPK. ${ }^{28} \mathrm{Smad} 2 / 3$ are transcription factors that bind DNA and directly regulate the expression of target genes, whereas p38 MAPK does not directly bind DNA, but regulates the activity of various transcription factors to control gene expression. ${ }^{21}$ In particular, Smad2/3 and p38 MAPK induce the synthesis of atrogin-1 and MuRF-1 - E3 ubiquitin ligases expressed in skeletal muscle that direct the polyubiquitination of proteins to target them for proteolysis by the $26 \mathrm{~S}$ proteasome, leading to muscle atrophy. ${ }^{28}$ Moreover, myostatin signaling can inhibit the PI3K-Akt axis and reduce $\mathrm{p} 70^{\mathrm{s} 6 \mathrm{k}}$ activation. ${ }^{29}$ Studies evaluating age-related changes of protein-degradation pathways in humans have shown increased serum levels of TGF $\beta$ and intramuscular levels of myostatin, but without differences in the expression of the E3 ubiquitin ligases atrogin-1 and MuRF-1. ${ }^{30}$ Although it could be difficult to draw a definitive conclusion, these results suggest that the ubiquitin proteasome system likely contributes to sarcopenia in humans. ${ }^{28}$

\section{Alterations in hormone levels and sensitivity}

Many hormones have metabolic effects on muscle mass and function. ${ }^{31}$ Sarcopenia is characterized by a variable decline of several hormones, especially sex hormones (eg, testosterone and dehydroepiandrosterone [DHEA]), growth hormone (GH), and IGF-1. ${ }^{5} \mathrm{GH} / \mathrm{IGF}-1$ levels are frequently reduced in elderly people and lead to changes in body composition, such as increased visceral fat as well as decreased lean body mass (LBM) and bone mineral density. ${ }^{32}$ However, the attempt to treat sarcopenic patients with GH injections did not result in an increased muscle strength but only in frequent side effects, ${ }^{33}$ although it has been demonstrated that systemic IGF-1 administration increases the rate of skeletal muscle functional recovery after injury. ${ }^{34}$ In addition, aging is associated with low testosterone levels, which may induce a decrease in muscle mass and bone strength, leading to more fractures and complications. ${ }^{32}$ Moreover, increasing age has been associated with elevated cortisol levels - a condition referred to as hypercortisolism. An increased exposure to corticosteroids - together with the reduction of the lipolytic effects of declining GH levels - may contribute to the age-dependent increase of visceral fat and decreased LBM and bone mineral density. ${ }^{35}$ Moreover, low levels of blood vitamin $\mathrm{D}$ are associated with decreased muscle strength seen in both sarcopenia and low physical activity ${ }^{32}$ Finally, elderly skeletal muscle is resistant to the anabolic action of insulin. ${ }^{36}$ Insulin resistance is a multifactorial condition wherein aging, obesity, and inflammation play a pivotal role: these conditions are linked to each other because aging is associated with a chronic inflammatory state, and obesity, superimposed on aging, drastically increases this chronic low-grade inflammation, thus contributing to insulin resistance and age-related conditions such as sarcopenia. ${ }^{37}$

Moreover, insulin resistance is part of a phenomenon known as anabolic resistance that leads to loss of skeletal muscle, which is the largest insulin-responsive target tissue, contributing to the exacerbation of insulin resistance itself. $^{32}$ As mentioned earlier, sarcopenia mainly affects the skeletal muscles of the lower limbs ${ }^{16}$ these findings are important to understand and prevent the effects of sarcopenia not only on quality of life and physical disabilities, but also on glucose homeostasis. In fact, an interesting study has shown higher glucose clearance in the arm than in the leg muscles and higher insulin resistance in the lower limb muscles of patients with type 2 diabetes (T2D). ${ }^{38}$ This phenomenon may be explained by the differences in the density of glucose transporter type 4 (GLUT4) in muscle fibers: in fact, in healthy individuals, GLUT4 has higher expression in slow than in fast muscle fibers, whereas, in T2D, GLUT4 has higher expression in fast, compared with slow, fibers. ${ }^{39,40}$ Given the higher proportion of fast type II muscle fibers in the upper body, this can explain the preserved glucose uptake and insulin sensitivity in the arm muscles in T2D. ${ }^{38}$ Because physical inactivity is one of the major risk factors in developing insulin resistance, 
it may be hypothesized that, through evolution, the upper body muscles have adapted to be less dependent on muscle usage. ${ }^{38}$ Finally, the difference between upper and lower body muscles could be explained by the lower vasodilator response to insulin in the legs as compared to the arms, with reduced recruitment of nutritive capillaries and, consequently, reduced glucose clearance. ${ }^{41}$ These differences between the upper and lower limbs are confirmed by the development of atherosclerosis, which is more prevalent and severe in the legs. ${ }^{38}$ Thus, further investigations are needed to explain these regional differences in insulin sensitivity and development of insulin resistance that exist in skeletal muscles of the human body.

\section{Inflammatory state and oxidative stress}

Aging is associated with a significant rise in serum levels of inflammatory markers, such as tumor necrosis factor-alpha (TNF- $\alpha$ ), interleukin (IL)-6, IL-1, and C-reactive protein (CRP). ${ }^{32}$ This state of chronic, low-grade, systemic inflammation in aging in the absence of infection is referred to as "inflammaging". ${ }^{42}$ This condition is suggested to predispose to sarcopenia through the activation of the ubiquitin-protease system, the reduction of the anabolic effect mediated by IGF-1, and the induction of anabolic resistance, which is one of the main determinants of sarcopenia. ${ }^{43}$ Specifically, anabolic resistance is the resistance of muscle protein anabolism to food intake. ${ }^{44}$ In physiological conditions, oral feeding leads to an increase in whole-body protein synthesis and a decrease in proteolysis, especially with regard to the anabolic effects exerted by amino acids and insulin. ${ }^{45}$ Sarcopenia and other muscle-wasting conditions are characterized, as discussed earlier, by an increase in catabolic factors (ie, cortisol, cytokines, and oxidative stress), which have potentially negative effects on amino acids or insulin signaling pathways involved in the stimulation of muscle anabolism after food intake, leading to an increased muscle "anabolic threshold". ${ }^{46}$ Moreover, aging is characterized by a chronic oxidative stress, which induces the consequent activation of the immune system and leads to an inflammatory state that creates a vicious circle wherein chronic oxidative stress and inflammation feed each other. ${ }^{47}$ Given the close relationship between inflammation, aging, and oxidative stress, the "oxi-inflamm-aging" theory of aging has been proposed. ${ }^{48}$ Skeletal muscles consume great quantities of oxygen, leading to a proportional generation of reactive species of nitrogen and oxygen (RONS), which is counteracted by the antioxidant system. ${ }^{49}$ Oxidative stress is thought to be a common determinant of sarcopenia, as shown by the increased RONS production in muscles, which can be explained by several mechanisms: the mitochondrial dysfunction caused by age-related mitochondrial DNA mutations, deletions, and damage; the impaired ability of muscle cells to remove dysfunctional mitochondria, which contributes to RONS production itself; and the decline in type II fibers, whose number of mitochondria is lower than in type I fibers. ${ }^{50}$ The increased production of RONS in skeletal muscle contributes to the pathogenesis of sarcopenia at different levels. In particular, RONS contributes to sarcopenia by increasing proteolysis and decreasing muscle protein synthesis, leading to a reduction in the muscle mass. ${ }^{51} \mathrm{~A}$ large number of studies have suggested the role of RONS in the reduction of the activity and/or sensitivity of the anabolic signaling pathway mediated by IGF-1, probably because of increased levels of TNF- $\alpha .{ }^{52}$ Moreover, forkhead transcription factors are a large family of proteins characterized by a conserved DNA-binding domain termed the "forkhead box" (FOXO) and FOXO1 inhibits the function of anabolic pathways in skeletal muscle via increased expression and reduced phosphorylation of the translational repressor protein 4E-BP1 and reduction in mTOR and raptor levels. ${ }^{53}$ Forkhead transcription factors are known to be aging-related transcription factors that are redox-regulated; thus, increased levels of these transcription factors are found in aged muscle and are associated with increased levels of atrogin-1 and MuRF-1 that lead to high rates of proteolysis. ${ }^{52}$ Finally, other mechanisms involved in RONS-mediated sarcopenia act at the NMJ: reduction of acetylcholine release at the synaptic cleft, leading to a failure in the generation of an action potential by the sarcolemma; reduction in the innervation and number of fibers of the NMJ itself; impairment of excitation-contraction coupling, leading to a lower release of calcium from the sarcoplasmic reticulum; and structural changes in actin and myosin structures reducing the cross-bridge cycling within the myofibrillar apparatus. ${ }^{54}$

\section{Behavioral factors}

Behavioral factors, such as nutritional status and physical inactivity, are very important reversible causes of sarcopenia. ${ }^{55}$

Reduction in appetite and/or food intake is commonly observed with aging and is referred to as anorexia of aging. ${ }^{56}$ This phenomenon is a result of age-related loss of appetite, sense of taste and smell, poor oral health, gastrointestinal changes (ie, delay in gastric emptying and elevated cholecystokinin levels), dementia, depression, disability, and social environment. ${ }^{55}$ Moreover, a decrease in neuropeptide Y (NPY) levels and function in the central nervous system 
as well as nitric oxide activity seems to play a key role in the anorexia of aging. ${ }^{57}$ This decline in food intake - and in protein consumption, in particular - contributes to muscle atrophy and to the severity of sarcopenia. ${ }^{56}$

At the same time, it is widely known that physical inactivity, such as due to bed rest during illness or the usual sedentary lifestyle, promotes the loss of muscle mass and strength, thereby worsening the degree of sarcopenia. ${ }^{58}$ In this regard, the Physical Activity Scale for the Elderly (PASE) is a self-reported tool to assess the routinely amount of occupational, home, and leisure physical activity for elderly people. ${ }^{59}$ A recent report on the relationship between sarcopenia and the PASE score in community-dwelling older adults showed that the PASE score is significantly lower in sarcopenic elderly subjects and is strictly related to low muscle mass and strength. ${ }^{60}$

\section{Diagnosis of sarcopenia}

According to the operational definition by the EWGSOP, the diagnosis of sarcopenia requires the presence of both low muscle mass and low muscle function, which can be defined by low muscle strength or low physical performance (Figure 1). ${ }^{61}$ In clinical practice, muscle strength can be evaluated by handgrip strength that is measured with a handheld dynamometer, whereas physical performance can be evaluated by usual gait speed and/or Short Physical Performance Battery (SPPB), which evaluates: the ability to stand with the feet together in side-by-side, semi-tandem, and tandem positions; time to walk 8 feet $(\sim 2.44 \mathrm{~m})$; and time to rise from a chair and return to the seated position five times. ${ }^{61,62}$ In presence of low muscle function, defined by a gait speed $<0.8 \mathrm{~m} / \mathrm{s}$ and/or a grip strength $<26-30 \mathrm{~kg}$ for men and $<16-20 \mathrm{~kg}$ for women, the diagnosis needs confirmation by muscle mass measurement. ${ }^{61}$ Muscle mass evaluation remains the main problem of a diagnosis of sarcopenia. ${ }^{5}$ Although dual energy X-ray absorptiometry (DEXA) ${ }^{63}$ and bioelectrical impedance analysis (BIA) ${ }^{64}$ are largely utilized for the assessment of skeletal muscle mass, MRI and computed tomography (CT) represent the gold standard and the most accurate imaging methods to provide not only an exact measurement of the mass of a muscle, but also important data on its density and fatty infiltration. ${ }^{65}$ Furthermore, skeletal muscle ultrasound (M-US) has been proposed for screening and diagnosing of sarcopenia in elderly individuals, although the current definitions of sarcopenia do not include it in diagnostic algorithms. ${ }^{61,66}$ A recent review of the literature about the role of M-US for detecting muscle mass loss in older individuals, has shown strengths and limitations of this technique. ${ }^{67}$ The main limitation is the absence of a standardized method of conducting the M-US: the type of ultrasonographic probe employed (linear or convex); ${ }^{68}$ the anatomic sites of measurement (lower or upper limb, abdomen); ${ }^{67}$ the position of patients during examinations (supine, prone, or standing in a rest position), ${ }^{69}$ the need for patients' collaboration to maintain a fixed posture during examination, which can be an important limitation for patients with mobilitydisability or cognitive impairment; ${ }^{67}$ the position, pressure, and inclination of the probe; ${ }^{68}$ and the type of parameters

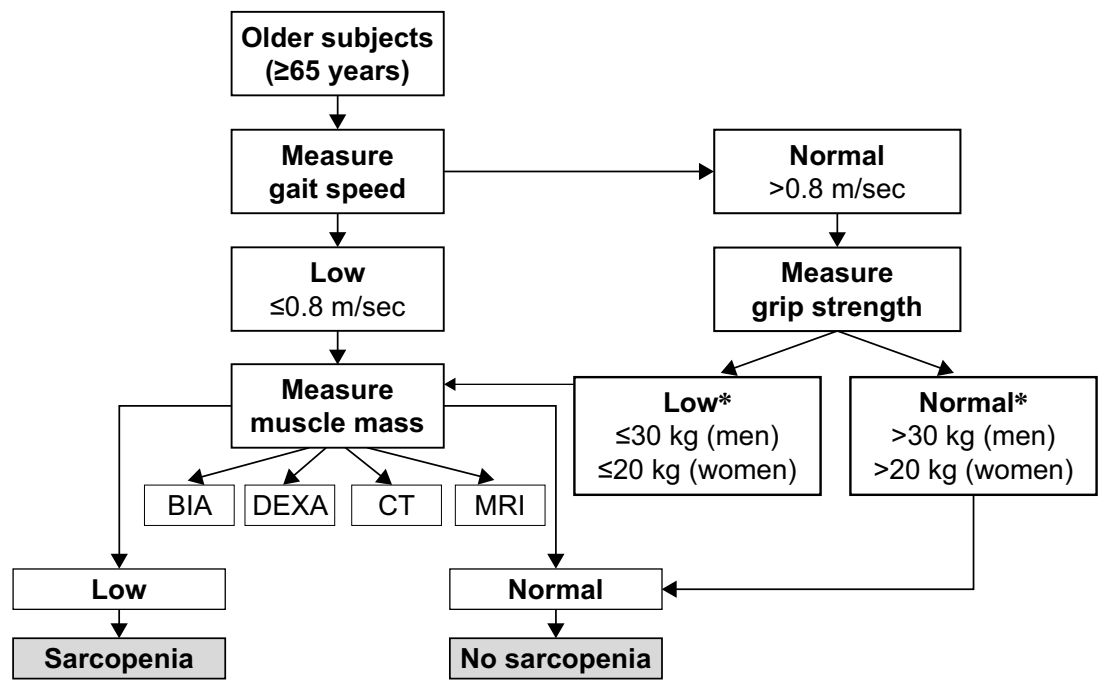

Figure I Sarcopenia assessment flowchart.

Note: (*) Body mass index (BMI)-adjusted values were used as a cutoff point to classify “Low” muscle strength $\left(\mathrm{BMI} \leq 24 \mathrm{~kg} / \mathrm{m}^{2}, 24 . \mathrm{I}-28 \mathrm{~kg} / \mathrm{m}^{2}\right.$, and $<28 \mathrm{~kg} / \mathrm{m}^{2}$ was $29 \mathrm{~kg} / \mathrm{m}^{2}$, $\leq 30 \mathrm{~kg} / \mathrm{m}^{2}$, and $\leq 32 \mathrm{~kg} / \mathrm{m}^{2}$ for men and BMI $\leq 23 \mathrm{~kg} / \mathrm{m}^{2}, 23.1-26 \mathrm{~kg} / \mathrm{m}^{2}, 26.1-29 \mathrm{~kg} / \mathrm{m}^{2}$, and $<29 \mathrm{~kg} / \mathrm{m}^{2}$ was $17 \mathrm{~kg} / \mathrm{m}^{2}, \leq 17.3 \mathrm{~kg} / \mathrm{m}^{2}, \leq 18 \mathrm{~kg} / \mathrm{m}^{2}$, and $\leq 21 \mathrm{~kg} / \mathrm{m}^{2}$ for women, respectively).

Abbreviations: BIA, bioelectrical impedance analysis; DEXA, dual energy X-ray absorptiometry; CT, computed tomography; MRI, magnetic resonance imaging. 
obtained (muscle thickness, cross-sectional area, fascicle length, pennation angle, and echo intensity). ${ }^{67}$ However, in none of the available studies were these parameters assessed together in the same individuals. Because simple, reproducible, and cost-effective techniques are needed for the early diagnosis of sarcopenia in older patients in everyday clinical practice, further investigations are needed to standardize this diagnostic technique before its use can be recommended in clinical practice although M-US has requisite characteristics to become a reference method for this evaluation.

Low muscle mass measured by DEXA is defined in the presence of a skeletal muscle mass index (SMI), defined as appendicular skeletal muscle mass (ASM)/height ${ }^{2}$ $\left(\mathrm{kg} / \mathrm{m}^{2}\right), \leq 7.26 \mathrm{~kg} / \mathrm{m}^{2}$ for men and $\leq 5.5 \mathrm{~kg} / \mathrm{m}^{2}$ for women. ${ }^{61}$ Muscle mass measured by BIA is calculated using the Janssen BIA equation:

$$
\begin{aligned}
& \text { Skeletal muscle mass }(\mathrm{kg}) \\
& \qquad \begin{aligned}
= & {\left[\text { Height }^{2} / \text { BIA resistance } \times 0.401\right] } \\
& +[\text { gender } \times 3.825]+[\text { age } \times(-0.71)]+5.102
\end{aligned}
\end{aligned}
$$

where height is measured in centimeters; BIA resistance is measured in ohms; for gender, men $=1$ and women $=0$; and age is measured in years. ${ }^{9}$ Starting from skeletal muscle mass, $\mathrm{SMI}=($ skeletal muscle mass/body mass $) \times 100$; low muscle mass is defined by a $\mathrm{SMI} \leq 8.87 \mathrm{~kg} / \mathrm{m}^{2}$ for men and $\leq 6.42 \mathrm{~kg} / \mathrm{m}^{2}$ for women. ${ }^{61}$

Moreover, in clinical practice, sarcopenia can be divided into "primary" and "secondary" types: it is defined as "primary" (or age-related) when no other cause can be identified except aging itself. Conversely, given the multifactorial pathogenesis of sarcopenia, it can be defined as "secondary" when one or more causes can be identified. Thus, we can distinguish: "activity-related sarcopenia", deriving from immobilization or sedentary lifestyle; "disease-related sarcopenia", associated with advanced organ failure, inflammatory disease, malignancy, or endocrine disease; and "nutrition-related sarcopenia", related to malnutrition, malabsorption, or gastrointestinal disorders. ${ }^{61}$ Furthermore, in clinical practice, sarcopenia staging can be useful to guide the clinical management of the condition according to the severity. The EWGSOP identifies three stages:

1) "Presarcopenia": characterized by low muscle mass and normal muscle strength or physical performance;

2) "Sarcopenia": characterized by both low muscle mass and low muscle strength or physical performance; and

3) "Severe sarcopenia": characterized by low muscle mass, low muscle strength, and low physical performance. ${ }^{61}$
Finally, according to the EWGSOP diagnostic criteria of sarcopenia, the pathophysiological mechanisms involved in its pathogenesis remain unexplored. ${ }^{5}$ In fact, the emerging priority has been to identify potential biomarkers for early detection of patients at risk for sarcopenia. The lack of a univocal definition for sarcopenia and its complex underlying pathophysiology make the development of biomarkers for this condition extremely challenging. ${ }^{70}$ Thus, in order to make a correct assessment of elderly patient with sarcopenia, biomarkers for each pathophysiological pathway have been identified, as shown in Table 1, and they can be divided into:

- Markers of NMJ degeneration such as C-terminal again fragment $(\mathrm{CAF})$, deriving from the inactivation of the agrin - a protein synthesized by motoneurons - with a consequent destabilization of the receptor for acetylcholine. ${ }^{5}$ In particular, circulating levels of CAF are much higher in sarcopenic subjects and are related to neuromuscular fatigue and loss of appendicular lean mass. ${ }^{71}$

- Markers of endocrine dysfunction include hormones involved in the regulation of muscle mass such as testosterone, DHEA, and the GH-IGF-1 axis. ${ }^{5}$

- Growth factors involved in muscle growth regulation, such as myostatin (MYO), activine A and B, growth differentiation factor-15 (GDF-15), bone morphogenetic proteins (BMPs), members of TGF- $\beta$ family; ${ }^{72-76}$ TGF- $\beta$ itself; ${ }^{76}$ follistatin (FST; the main inhibitor of MYO), ${ }^{77}$ and brain-derived neurotrophic factor (BDNF); ${ }^{78}$

- Markers of muscle protein turnover including neoepitopes, such as sarcomeric proteins (actin, myosin, troponin, and tropomyosin) and extracellular matrix proteins as well as type VI collagen N-terminal globular domain epitope (IC6), MMP-generated degradation fragment of collagen 6 (C6M), N-terminal peptide (P3NP); ${ }^{79,80}$ 3-methylhistidine $(3 \mathrm{MH})$, skeletal muscle-specific isoform of troponin $\mathrm{T}$ (sTnT), and creatinine. ${ }^{5}$

- Markers of physical inactivity such as complement protein $\mathrm{C1q}$, hemoglobin, albumin, selenium, leptin, uric acid, magnesium, and vitamin D. ${ }^{81-88}$

- Markers of inflammation and oxidative stress: IL-6, IL-1, TNF- $\alpha$, butyryl-cholinesterase (b-CHE), oxidized low density lipoprotein (OxLDL), and vitamins C and E. ${ }^{89-93}$ Although the levels of these current available biomarkers are altered during sarcopenia, given their lack of specificity and sensitivity, they cannot be used alone for the diagnosis of sarcopenia. Moreover, these biomarkers are only able to capture single aspects of this condition and are weakly associated with clinically meaningful aspects. ${ }^{70}$ Nevertheless, 
Table I Overview of the most important biomarkers of sarcopenia

\begin{tabular}{|c|c|c|c|c|c|}
\hline Biomarker & Year & Pathogenesis & Increased & Decreased & References \\
\hline Follistatin & 2001 & Muscle growth promoter & & $\mathrm{X}$ & 142 \\
\hline Vitamin D & 2003 & Inadequate intake & & $\mathrm{X}$ & 87 \\
\hline Hemoglobin & 2004 & Intake inadequate/underproduction & & $\mathrm{X}$ & 82 \\
\hline Bone morphogenetic proteins & 2005 & Muscle growth promoter & & $X$ & 75 \\
\hline Albumin & 2005 & Intake inadequate/underproduction or lack & & $\mathrm{X}$ & 83 \\
\hline Oxidized low-density lipoprotein & 2005 & Pro-oxidant & $X$ & & 92 \\
\hline Testosterone & 2006 & Muscle growth promoter & & $\mathrm{X}$ & 80 \\
\hline Magnesium & 2006 & Inadequate intake & & $X$ & 86 \\
\hline Selenium & 2007 & Intake inadequate & & $\mathrm{X}$ & 84 \\
\hline$C-E$ vitamin & 2007 & Antioxidant & & $X$ & 93 \\
\hline Myostatin & 2008 & Muscle growth suppressor & $X$ & & 143 \\
\hline Insulin-like growth factor I & 2008 & Muscle growth promoter & & $X$ & 34 \\
\hline Uric acid & 2008 & Inadequate intake & & $X$ & 144 \\
\hline N-terminal type III procollagene & 2009 & Muscle remodeling & & $X$ & 80 \\
\hline Leptin & 2010 & Obesity & $x$ & & 85 \\
\hline Brain-derived neurotrophic factor & 2012 & Muscle growth promoter & & $X$ & 145 \\
\hline Growth hormone & 2012 & Muscle growth promoter & & $X$ & 146 \\
\hline Interleukin 6 & 2012 & Inflammation & $x$ & & 89 \\
\hline Tumor necrosis factor $\alpha$ & 2012 & Inflammation & & $X$ & 90 \\
\hline Interleukin I & 2012 & Inflammation & & $X$ & 90 \\
\hline Growth differentiation factor- 15 & 2013 & Muscle growth suppressor & $x$ & & 74 \\
\hline 3-methylhistidine & 2013 & Proteolysis of myofibrils & $X$ & & 147 \\
\hline Creatinine & 2013 & Muscle turnover reduction & & $\mathrm{X}$ & 148 \\
\hline Activins $A$ and $B$ & 2014 & Muscle growth suppressor & $x$ & & 73 \\
\hline Tumor growth factor $\beta$ & 2014 & Muscle growth suppressor & $X$ & & 76 \\
\hline Skeletal muscle-specific troponin $T$ & 2014 & Contractile insufficiency & $x$ & & 149 \\
\hline Butyryl-cholinesterase & 2014 & Inflammation & & $X$ & 91 \\
\hline C-terminal agrin fragment & 2014 & Impairment of neuromuscular junctions & $X$ & & II \\
\hline Dehydroepiandrosterone & 2015 & Muscle growth promoter & & $X$ & 150 \\
\hline Complement protein $\mathrm{Cl} q$ & 2015 & Physical inactivity & $\mathrm{X}$ & & 81 \\
\hline
\end{tabular}

the adoption of a multidimensional approach - wherein the diagnosis of sarcopenia according to the EWGSOP criteria is supported by the routine assessment of these biomarkers could help to identify the different domains affected by this syndrome and, consequently, allow a personalized follow-up to evaluate the effectiveness of prevention and treatment measures. 5,70

\section{Frailty and sarcopenia: an intriguing relationship}

Different criteria have been validated to identify frail older subjects, which mainly refer to two conceptual models: the cumulative deficit approach proposed by Rockwood and Mitnitski" and the "Frailty phenotype" proposed by Fried et al. ${ }^{95}$ Both models have received empirical validation. Actually, the frailty proposed by Rockwood is defined as "multidimensional frailty" and is characterized by four domains (physical, mental, nutritional, and socioeconomic). ${ }^{96}$ Nevertheless, the "Frailty phenotype" is surely the most widely used and presents a better characterized pathophysiological background; it is particularly useful for the clinical screening of "physical frailty" (PF) in the context of preventive interventions. ${ }^{97}$ According to Fried's criteria, a phenotype of frailty is identified by the presence of three or more of the following components:

1) Shrinking: unintentional weight loss of $\geq 4.5 \mathrm{~kg}$ in the preceding year or, at follow-up, loss of $\geq 5 \%$ of body weight from that in the previous year (by direct measurement of weight);

2) Weakness: grip strength value, adjusted for gender and body mass index;

3) Poor endurance and energy: as indicated by self-reported exhaustion, identified by two items derived from the CES-D scale ("I felt that everything I did was an effort"; "I could not get going"); 98

4) Slowness: based on time to walk $4 \mathrm{~m}$, adjusted for gender and standing height;

5) Low physical activity level: a score of kilocalories expended per week (males: <383 kcals/week; females: 270 kcals/week). ${ }^{95}$ 


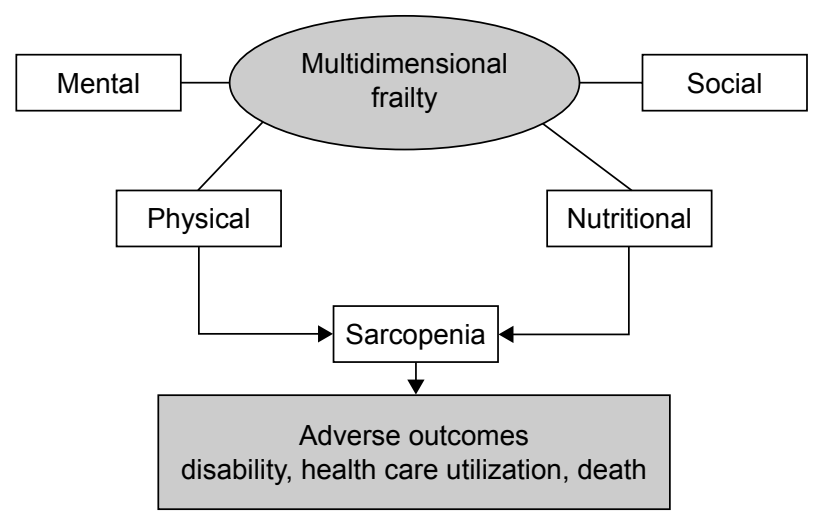

Figure 2 Relationship between sarcopenia and frailty (see the text for details).

The PF depicted by the "Frailty phenotype" has been shown to be predictive of major negative health-related outcomes, including mobility-disability, disability for activities of daily living, institutionalization, and mortality. ${ }^{97}$ At the same time, it cannot be ignored that the PF presents substantial overlaps with sarcopenia. In fact, many of the adverse outcomes of frailty are probably mediated by sarcopenia, which may be considered the biological substrate for the development of PF and related negative health outcomes (Figure 2). Although PF encompasses only a part of the frailty spectrum, the identification of a definite biological basis (ie, sarcopenia) opens new views for the development of interventions to slow or reverse the progression of this condition. ${ }^{99}$

\section{Therapeutic approaches}

Sarcopenia is an important geriatric syndrome which increases the risk of negative consequences such as physical disability, poor quality of life, and death, especially in institutionalized elderly residents of nursing homes. ${ }^{100,101}$ In particular, a recent systematic review to assess the consequences of sarcopenia reported approximately six different types of adverse outcomes: mortality, functional decline, falls, fracture, length of hospital stay, and hospitalization. ${ }^{102}$ Moreover, because sarcopenia can be assessed objectively and predicts frailty, poor quality of life, and mortality, ${ }^{96}$ it could be used as a predictor of these adverse health outcomes and as a therapeutic target in the elderly with regard to prevention. ${ }^{103}$

According to the pathophysiological factors involved in the pathogenesis of sarcopenia, we can identify different treatment strategies that are summarized in Figure 3 and are mainly aimed to correct behavioral and endocrine causes.

\section{Exercise}

As mentioned earlier, physical inactivity and disease - both highly prevalent in the elderly - are the main contributors to the decline of muscle mass and function. ${ }^{104}$ Both resistance and aerobic training have been shown to increase muscle strength and improve physical function. ${ }^{2}$ In particular, in the early 1990s, a series of innovative studies established the role of progressive resistance exercise training (PRT) in increasing muscle strength, muscle size, and functional capacity in the elderly. ${ }^{105,106}$ In PRT, subjects exercise their muscles against an increasing external force, and this is undertaken at least 2-3 times a week for 8-12 weeks and the duration of sessions and number of exercises increases gradually over time based on each individual's capability and improvement. ${ }^{2}$ In 1990 ,

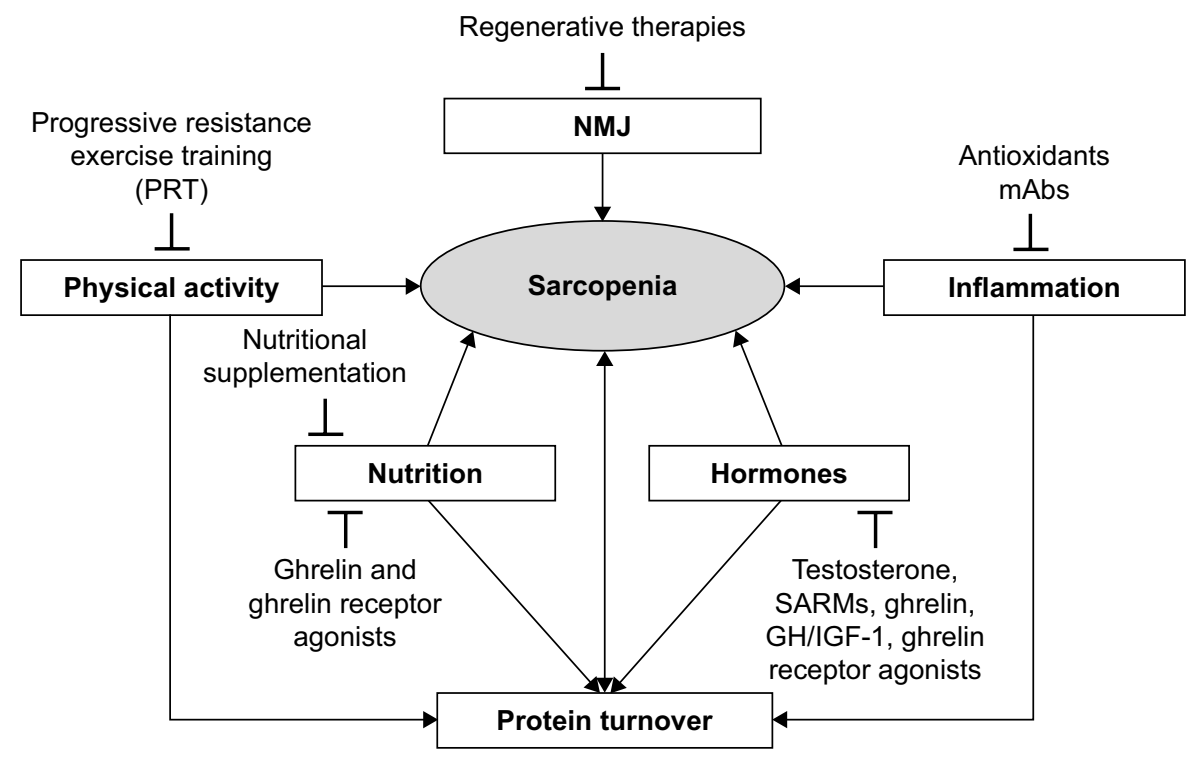

Figure 3 Sarcopenia: pathogenesis and relative therapeutic approaches.

Abbreviations: NMJ, neuromuscular junction; SARMs, selective androgen receptor modulators; GH/IGF, growth hormone and insulin-like growth factor; mAbs, monoclonal antibodies. 
Fiatarone et al established the efficacy of PRT in improving muscle mass, muscle strength, and gait speed. ${ }^{105}$ In 2009, a Cochrane review on 121 trials concluded that PRT improves muscle strength as well as physical performance, including gait speed and getting up from a chair. So far, no other treatment proposed and investigated for the prevention and improvement of sarcopenia has shown better results than PRT. ${ }^{2}$ Accordingly, PRT should be considered a first-line treatment strategy for managing and preventing sarcopenia and its adverse health outcomes. Nevertheless, the implementation of PRT in community-dwelling elderly patients is still underused because it requires trained therapists and special equipment that are not routinely available. ${ }^{2}$

\section{Nutrition}

There is no doubt that malnutrition is involved in the pathogenesis of sarcopenia, and that it contributes to the poor muscle function observed in many older adults, particularly in frail elderly patients. ${ }^{104}$ Food intake declines progressively between 20 and 80 years by $\sim 1.300$ and $600 \mathrm{kcal}$ in men and women, respectively, ${ }^{107}$ because of several age-related conditions, including masticatory disability, drugs, physiological anorexia, and changes in eating habits with a predilection for energy-dilute foods, such as grains, vegetables, and fruits, in place of energy-dense carbohydrates and protein-rich nutrients. ${ }^{70}$ As a consequence of these factors, the prevalence of malnutrition ranges from $5 \%$ to $20 \%$ in community-dwelling older adults and exceeds $60 \%$ in the institutionalized elderly. ${ }^{108}$ These findings have led to the proposition of nutritional interventions based on the delivery of an adequate energy supply (ie, 24-36 kcal/kg/day) and on the supplementation of specific nutrients as effective treatment in preventing and/or reversing sarcopenia. ${ }^{74}$ The main nutritional strategies proposed for the treatment of sarcopenia include:

- Increased protein intake

An increase in protein intake above $0.8 \mathrm{~g} / \mathrm{kg} /$ day, specifically a daily protein intake of $1.0 \mathrm{~g} / \mathrm{kg}$, has been identified as the minimum amount required to maintain muscle mass in old age. ${ }^{109,110}$ Increased protein intake may enhance muscle mass and function. ${ }^{111}$ Moreover, the amino acid composition of dietary proteins influences the metabolism of muscle protein. In fact, as mentioned earlier, essential amino acids are the primary stimulus for protein synthesis. Thus, elderly patients should be recommended to consume protein sources containing a relatively high proportion of amino acids - the so-called high-quality proteins. ${ }^{112}$ In particular, there are some evidences for synergistic effects of exercise and protein to enhance muscle function. ${ }^{111}$

\section{- Vitamin D supplementation}

Serum levels of vitamin D decline with aging and approximately over one billion people worldwide have vitamin D deficiency or insufficiency. ${ }^{113}$ Moreover, vitamin D influences muscle metabolism and tropism and its deficiency is related to sarcopenia. ${ }^{12}$ Evidences about the utility of supplementation with calcium and vitamin D are still controversial. A 2009 meta-analysis showed a $19 \%$ risk reduction in falls in elderly people taking at least $700 \mathrm{IU}$ supplemental vitamin D per day. ${ }^{114}$ Based on these findings, it is currently recommended to measure serum levels of 25-hydroxy vitamin D in all sarcopenic patients and to prescribe vitamin D supplements (800 IU $[20 \mu \mathrm{g}] /$ day) to those with values lower than $100 \mathrm{nmol} / \mathrm{L}$ $(40 \mathrm{ng} / \mathrm{mL}) .{ }^{112}$

- Creatine monohydrate

Creatine $(\mathrm{Cr})$ monohydrate has emerged as an efficient nutritional supplement capable of improving muscle mass and performance in older adults when combined with resistance exercise. ${ }^{112}$ Therefore, short-term $\mathrm{Cr}$ supplementation (5-20 g/day of $\mathrm{Cr}$ monohydrate for 2 weeks) may be advisable in older persons engaged in strength-training programs. ${ }^{115}$

- Antioxidants

According to the "oxi-inflamm-aging" theory of aging ${ }^{48}$ and the involvement of oxidative stress in the pathogenesis of sarcopenia, the administration of antioxidative agents (ie, selenium, vitamin E, and vitamin C) has been proposed for the management of sarcopenia. ${ }^{112}$ In the InCHIANTI study - a population-based study of older persons living in the Chianti geographic area (Tuscany, Italy) - higher plasma levels of antioxidants were associated with a lower risk of developing disability and declining muscle strength. ${ }^{93}$ Unfortunately, redox physiology is not as clear as it appears. In fact, commonly prescribed antioxidants (ie, selenium, vitamin A, vitamin C, vitamin $\mathrm{E}$, and $\beta$-carotene) may paradoxically behave as potent pro-oxidants to increase the risk of mortality. ${ }^{116}$

- Other nutritional strategies

Several novel dietary candidates and nutrition strategies against sarcopenia have been proposed and need further investigations:

- $\beta$-hydroxy $\beta$-methylbutyrate (HMB): a metabolite of leucine that is receiving increasing attention as a potential nutritional aid against sarcopenia. ${ }^{117}$

- Ornithine $\alpha$-ketoglutarate (OKG): the precursor of several amino acids (ie, glutamate, glutamine, arginine, and proline) and of other bioactive compounds (ie, polyamines, citrulline, $\alpha$-ketoisocaproate, and nitric oxide) that are 
important modulators of muscle protein metabolism and hemodynamics. ${ }^{112}$

- Omega-3 fatty acids: polyunsaturated fatty acids (PUFAs), which have been showed to improve muscle protein synthesis and grip strength, ${ }^{118,119}$ suggesting that an adequate intake of omega- 3 fatty acids could represent an effective nutritional remedy for sarcopenia.

- Caloric restriction (CR) and regular physical exercise exert beneficial effects on overall health and muscle homeostasis in advanced age. ${ }^{120}$ However, long-term CR could induce a weight loss that may be harmful in non-obese elderly, thereby accelerating muscle loss and increasing the risk of disability and mortality. ${ }^{121}$ Recent studies have detected bioactive substances from plant sources (eg, fruits, vegetables, grains, herbs, and spices) that could mimic the signaling pathways involved in some of the effects of CR and physical exercise. ${ }^{122}$ These dietary-derived "CR mimetics" (CRMs) and "exercise mimetics" (EMs) are phytochemicals with well-recognized antioxidant properties; however, despite some encouraging findings, the field of CRMs and EMs is still under investigation. ${ }^{112}$

- The human gut microbiota is composed of $\sim 10^{14}$ microorganisms, including bacteria, viruses, fungi, and protozoa, with a gene pool 150-fold larger than that of the host. ${ }^{123}$ Alterations in the gut microbiota could contribute to the etiopathogenesis of sarcopenia, because it can also influence the host physiology by modulating systemic inflammation, anabolism, insulin sensitivity, and energy production. ${ }^{112}$ However, malnutrition and physical inactivity may influence microbiota composition. ${ }^{124}$ Only one randomized controlled trial, enrolling 60 older patients, investigated the benefits on skeletal muscle outcomes of the administration of a prebiotic formulation (fructo-oligosaccharides and inulin) versus placebo for 13 weeks, showing unexpectedly that the treatment group experienced improvement in two outcomes of muscle function: exhaustion and handgrip strength. ${ }^{125}$ Although these data support the hypothesis of a modulation of muscle function by gut microbiota, unfortunately, no other study has explored this field to date. Nevertheless, the literature supports the possible presence of a "gut-muscle axis" and this hypothesis should be further investigated. ${ }^{124}$

\section{Testosterone}

Testosterone levels decline by $\sim 1 \%$ per year from 30 years of age, and this decline is associated with a reduction in muscle mass and strength. ${ }^{11}$ Several studies have shown the beneficial effects of testosterone supplementation on muscle and bone tissues: ${ }^{126}$ in particular, it may increase muscle strength and physical performance and decrease fat mass and hospitalization in older adults. ${ }^{111}$ In lower doses, testosterone increases protein synthesis, thereby resulting in an increase in muscle mass, ${ }^{127}$ and, in high doses, testosterone activates satellite cell recruitment and reduces adipose stem cells, thus increasing myogenesis and decreasing adipogenesis. ${ }^{111}$ Testosterone replacement in the elderly is associated with several possible side effects, such as CVDs, fluid retention, gynecomastia, worsening of sleep apnea, polycythemia, and acceleration of benign or malignant prostatic disease. ${ }^{128,129}$ Nevertheless, among the drugs investigated for the treatment of sarcopenia, testosterone is the most effective and safest, because its adverse effects are dose-dependent and associated with very high doses of 300 and $600 \mathrm{mg} /$ week. ${ }^{111,126}$ Two major trials are ongoing and could help determine the role of testosterone in the management of sarcopenia (The Testosterone Trial in Older Men and the T4DM trial).

\section{Selective androgen receptor modulators}

Dose-dependent adverse effects related to testosterone supplementation have driven the development of therapeutic agents with anabolic effects specific for skeletal muscle and bone tissues. ${ }^{130}$ Selective androgen receptor modulators (SARMs) are a class of androgen receptor ligands that show androgenic effects in some tissues (eg, muscle and bone) and without effects on other organs, such as the prostate or skin, thereby limiting adverse effects such as prostate growth or androgenization. ${ }^{112}$ Structurally, SARMs can be categorized into steroidal and nonsteroidal SARMs. ${ }^{130}$ Steroidal SARMs were first developed in the 1940s by modifying the chemical structure of the testosterone molecule, but they showed adverse effects similar to those of testosterone itself. ${ }^{111}$ The modern era of nonsteroidal SARMs has emerged due to the efforts of scientists at Ligand Pharmaceuticals and the University of Tennessee. ${ }^{130}$ Actually, a number of steroidal and non-steroidal SARMs have undergone Phase I-III trials. ${ }^{92}$ A 12-week double-blind, placebo-controlled Phase II clinical trial conducted to evaluate GTx-024 (enobosarm) in 120 healthy elderly men and postmenopausal women showed a dose-dependent improvement in total LBM and physical function and was well tolerated. ${ }^{131}$ Moreover, a 21-day ascending dose study of LGD-4033 (ligandrol) in healthy young men showed that the drug was well tolerated, had a favorable pharmacokinetic profile, and increased LBM and leg press strength. ${ }^{132}$ Another SARM, MK-773, has undergone Phase II studies in both men and women with 
sarcopenia. In one study enrolling women aged 65 or older with sarcopenia and frailty, the treatment with MK-0773 produced statistically significant increases in LBM compared to placebo, but no significant improvement in strength or function. ${ }^{133}$ Although SARMs appear to be safe and effective in increasing LBM and possibly strength and function, their effects on muscle mass and function have been modest in comparison to the effects deriving from treatment with high doses of testosterone. ${ }^{134}$ Trials including long-term followups and/or more effective and selective SARMs are needed to demonstrate long-term safety and efficacy of SARMs in improving physical function and health outcomes. ${ }^{133}$

\section{GH/IGF-I}

$\mathrm{GH}$ administration, which produces its effects through the release of liver-derived IGF-1, increases LBM but not muscle strength in the elderly, and it is associated with a variety of side effects including joint and muscle pain, edema, carpal tunnel syndrome, and hyperglycemia. ${ }^{135}$ As for IGF-1 administration, a single small study in elderly subjects found an increase in side effects (ie, orthostatic hypotension, gynecomastia, myositis, and edema) and in the risk of CVDs. ${ }^{136}$

\section{Ghrelin and ghrelin receptor agonists}

Ghrelin is produced from the fundus of the stomach, increasing food intake and $\mathrm{GH}$ secretion. ${ }^{111}$ Several studies involving ghrelin or ghrelin receptor agonists (ie, anamorelin and capromorelin) have shown positive effects in increasing food intake and muscle mass and function (tandem walk and stair climb). ${ }^{2}$ More trials are needed to establish the efficacy and safety of these agents in the long-term treatment of sarcopenia because, whereas ghrelin agonists will increase food intake and muscle mass, it is unlikely that they will produce a significant effect on function in persons with sarcopenia.

\section{Angiotensin-converting enzyme inhibitor}

Some drugs, involved in the treatment of congestive heart failure to improve functional performance and prognosis, are under investigation for skeletal muscle preservation - in particular, angiotensin-converting enzyme inhibitors (ACE-Is). ${ }^{2}$ Among ACE-Is, perindopril has shown to increase physical performance, in particular 6-minute walking distance, and to reduce the incidence of hip fractures in elderly subjects. ${ }^{111}$ In particular, in a double-blind randomized controlled trial evaluating the effect of perindopril on the 6-minute walking distance in elderly subjects with functional impairment, perindopril improved exercise capacity, showing a degree of improvement equivalent to that reported after 6 months of exercise training. ${ }^{137}$ The LACE study (Leucine and ACE inhibitors in sarcopenia) will evaluate the efficacy of leucine and perindopril in elderly patients with sarcopenia from primary and secondary care services across the UK, using the difference in SPPB and DEXA between baseline and 12 months. The results will provide the overall clinical and cost-effectiveness of these novel therapies for older patients with sarcopenia. ${ }^{138}$

\section{Future therapeutic approaches}

Recent developments in sarcopenia therapeutic interventions have evaluated several promising agents, such as the SARM enobosarm and the ghrelin receptor agonist anamorelin, whose Phase III clinical trials have showed significant effect on increasing muscle mass in patients with sarcopenia. Given the role of the pro-inflammatory cytokines (ie, TNF- $\alpha$, IL-1, IL-6) and myokines in the pathogenesis of sarcopenia, as well as anti-inflammatory agents, such as the monoclonal antibodies infliximab, tocilizumab, and bimagrumab, appear promising. However, these agents have shown significant impact on reversal of skeletal muscle loss, but have limited effect on physical function. ${ }^{139}$

Another promising alternative therapeutic approach includes regenerative medicine strategies. Sarcopenia is attributable also to loss of functional contractile myofibrillar units. These findings have driven the investigation of utilizing exogenous delivery of stem/progenitor cells to stimulate myogenesis. To date, little success has been achieved by the use of different stem cells (eg, satellite cells, muscle-derived, perivascular, embryonic, and induced pluripotent stem cells) for skeletal muscle repair, in particular in preclinical studies; moreover, the clinical utility of stem-cell-based approaches show technical, economic, and regulatory difficulties. ${ }^{140}$ In addition, the microenvironment plays a significant role in contributing to the proliferation of stem cells and regeneration of skeletal muscle. ${ }^{141}$ The evidence that changing the environment of aged myogenic progenitor cells can promote skeletal muscle regeneration is supporting the investigation of extracellular matrix bioscaffolds delivered by nanovescicles as an attractive solution for the treatment of age-related muscle loss. ${ }^{140}$ These approaches could provide improved outcomes for patients suffering from age-related muscle loss but are still under investigation.

\section{Conclusion}

Sarcopenia is a geriatric syndrome characterized by the loss of both muscle mass and strength and it is associated with a series of adverse economic and social implications, such as disability, hospitalization, and death; therefore, it is related to increased total health care expenditure. Several 
therapeutic strategies have been proposed according to the multifactorial pathogenesis of sarcopenia: physical exercise training, nutritional interventions, hormonal therapies (ie, androgens, SARMs, GH/IGF-1, ghrelin, and ghrelin receptor agonists), and ACE-I. Novel strategies are still under investigation and specifically involve stem cells or anti-inflammatory agents (eg, infliximab, tocilizumab). However, at the present time, only physical exercise has shown a positive effect in managing and preventing sarcopenia and its adverse health outcomes. Actually, the positive additional effect of nutritional supplementation has been reported in a limited number of studies. In fact, studies assessing the impact of a both exercise and dietary interventions are still lacking in frail and sarcopenic populations. Nevertheless, the implementation of physical exercise or nutritional strategies in community-dwelling elderly are still underused because they require trained health care professionals and special equipment that are not routinely available. Thus, further studies on these types of population should be conducted.

\section{Disclosure}

The authors report no conflicts of interest in this work.

\section{References}

1. Steenman M, Lande G. Cardiac aging and heart disease in humans. Biophys Rev. 2017;9(2):131-137.

2. Ali S, Garcia JM. Sarcopenia, cachexia and aging: diagnosis, mechanisms and therapeutic options - a mini-review. Gerontology. 2014;60(4): 294-305.

3. Nakou ES, Simantirakis EN, Kallergis EM, Skalidis EI, Vardas PE. Long-standing sinus arrest due to the occlusion of sinus node artery during percutaneous coronary intervention: clinical implications and management. Int J Cardiol. 2016;203:432-433.

4. Flatt T. A new definition of aging? Front Genet. 2012;3:148.

5. Curcio F, Ferro G, Basile C, et al. Biomarkers in sarcopenia: a multifactorial approach. Exp Gerontol. 2016;85:1-8.

6. Morley JE, Baumgartner RN, Roubenoff R, Mayer J, Nair KS. Sarcopenia. J Lab Clin Med. 2001;137(4):231-243.

7. Rosenberg IH. Sarcopenia: origins and clinical relevance. J Nutr. 1997; 127(5 Suppl):990S-991S.

8. Volpato S, Bianchi L, Cherubini A, et al. Prevalence and clinical correlates of sarcopenia in community-dwelling older people: application of the EWGSOP definition and diagnostic algorithm. J Gerontol A Biol Sci Med Sci. 2014;69(4):438-446.

9. Janssen I, Heymsfield SB, Baumgartner RN, Ross R. Estimation of skeletal muscle mass by bioelectrical impedance analysis. $J$ Appl Physiol (1985). 2000;89(2):465-471.

10. Roubenoff R. Sarcopenia and its implications for the elderly. Eur J Clin Nutr. 2000;54 Suppl 3:S40-S47.

11. Gonzalez-Freire M, de Cabo R, Studenski SA, Ferrucci L. The neuromuscular junction: aging at the crossroad between nerves and muscle. Front Aging Neurosci. 2014;6:208.

12. Rowan SL, Rygiel K, Purves-Smith FM, Solbak NM, Turnbull DM, Hepple RT. Denervation causes fiber atrophy and myosin heavy chain co-expression in senescent skeletal muscle. PLoS One. 2012;7(1):e29082.

13. Chai RJ, Vukovic J, Dunlop S, Grounds MD, Shavlakadze T. Striking denervation of neuromuscular junctions without lumbar motoneuron loss in geriatric mouse muscle. PLoS One. 2011;6(12):e28090.
14. Luff AR. Age-associated changes in the innervation of muscle fibers and changes in the mechanical properties of motor units. Ann N Y Acad Sci. 1998;854:92-101.

15. Lexell J. Human aging, muscle mass, and fiber type composition. J Gerontol A Biol Sci Med Sci. 1995;50 Spec No:11-16.

16. Narici MV, Maffulli N. Sarcopenia: characteristics, mechanisms and functional significance. Br Med Bull. 2010;95:139-159.

17. Rudolf R, Khan MM, Labeit S, Deschenes MR. Degeneration of neuromuscular junction in age and dystrophy. Front Aging Neurosci. 2014;6:99.

18. Punga AR, Ruegg MA. Signaling and aging at the neuromuscular synapse: lessons learnt from neuromuscular diseases. Curr Opin Pharmacol. 2012;12(3):340-346.

19. García ML, Fernández A, Solas MT. Mitochondria, motor neurons and aging. J Neurol Sci. 2013;330(1-2):18-26.

20. Sandri M. Signaling in muscle atrophy and hypertrophy. Physiology (Bethesda). 2008;23:160-170.

21. Schiaffino S, Dyar KA, Ciciliot S, Blaauw B, Sandri M. Mechanisms regulating skeletal muscle growth and atrophy. FEBS J. 2013;280(17): 4294-4314.

22. Bentzinger CF, Romanino K, Cloëtta D, et al. Skeletal muscle-specific ablation of raptor, but not of rictor, causes metabolic changes and results in muscle dystrophy. Cell Metab. 2008;8(5):411-424.

23. Deldicque L, Theisen D, Francaux M. Regulation of mTOR by amino acids and resistance exercise in skeletal muscle. Eur J Appl Physiol. 2005;94(1-2):1-10.

24. Sharples AP, Hughes DC, Deane CS, Saini A, Selman C, Stewart CE. Longevity and skeletal muscle mass: the role of IGF signalling, the sirtuins, dietary restriction and protein intake. Aging Cell. 2015;14(4): 511-523.

25. Latres E, Amini AR, Amini AA, et al. Insulin-like growth factor-1 (IGF-1) inversely regulates atrophy-induced genes via the phosphatidylinositol 3-kinase/Akt/mammalian target of rapamycin (PI3K/Akt/ mTOR) pathway. J Biol Chem. 2005;280(4):2737-2744.

26. Jefferson LS, Kimball SR. Amino acids as regulators of gene expression at the level of mRNA translation. $J$ Nutr. 2003;133(6 Suppl 1): 2046S-2051S.

27. Pallafacchina G, Calabria E, Serrano AL, Kalhovde JM, Schiaffino S. A protein kinase B-dependent and rapamycin-sensitive pathway controls skeletal muscle growth but not fiber type specification. Proc Natl Acad Sci U S A. 2002;99(14):9213-9218.

28. Gumucio JP, Mendias CL. Atrogin-1, MuRF-1, and sarcopenia. Endocrine. 2013;43(1):12-21.

29. Amirouche A, Durieux AC, Banzet S, et al. Down-regulation of Akt/ mammalian target of rapamycin signaling pathway in response to myostatin overexpression in skeletal muscle. Endocrinology. 2009;150(1): 286-294.

30. Whitman SA, Wacker MJ, Richmond SR, Godard MP. Contributions of the ubiquitin-proteasome pathway and apoptosis to human skeletal muscle wasting with age. Pflugers Arch. 2005;450(6):437-446.

31. Yu J. The etiology and exercise implications of sarcopenia in the elderly. Int J Nurs Sci. 2015;2(2):199-203.

32. Kim TN, Choi KM. Sarcopenia: definition, epidemiology, and pathophysiology. J Bone Metab. 2013;20(1):1-10.

33. Papadakis MA, Grady D, Black D, et al. Growth hormone replacement in healthy older men improves body composition but not functional ability. Ann Intern Med. 1996;124(8):708-716.

34. Giovannini S, Marzetti E, Borst SE, Leeuwenburgh C. Modulation of GH/IGF-1 axis: potential strategies to counteract sarcopenia in older adults. Mech Ageing Dev. 2008;129(10):593-601.

35. Nass R, Thorner MO. Impact of the GH-cortisol ratio on the agedependent changes in body composition. Growth Horm IGF Res. 2002; 12(3):147-161.

36. Rasmussen BB, Fujita S, Wolfe RR, et al. Insulin resistance of muscle protein metabolism in aging. FASEB J. 2006;20(6):768-769.

37. Frasca D, Blomberg BB, Paganelli R. Aging, obesity, and inflammatory age-related diseases. Front Immunol. 2017;8:1745. 
38. Olsen DB, Sacchetti M, Dela F, Ploug T, Saltin B. Glucose clearance is higher in arm than leg muscle in type 2 diabetes. JPhysiol. 2005;565(Pt 2): 555-562.

39. Gaster M, Staehr P, Beck-Nielsen H, Schrøder HD, Handberg A. GLUT4 is reduced in slow muscle fibers of type 2 diabetic patients: is insulin resistance in type 2 diabetes a slow, type 1 fiber disease? Diabetes. 2001;50(6):1324-1329.

40. Gaster M, Poulsen P, Handberg A, Schrøder HD, Beck-Nielsen H. Direct evidence of fiber type-dependent GLUT-4 expression in human skeletal muscle. Am J Physiol Endocrinol Metab. 2000;278(5):E910-E916.

41. Newcomer SC, Leuenberger UA, Hogeman CS, Handly BD, Proctor DN. Different vasodilator responses of human arms and legs. $J$ Physiol. 2004;556(Pt 3):1001-1011.

42. Franceschi $C$, Bonafè $M$, Valensin $S$, et al. Inflamm-aging. An evolutionary perspective on immunosenescence. Ann N Y Acad Sci. 2000;908: 244-254.

43. Ogawa S, Yakabe M, Akishita M. Age-related sarcopenia and its pathophysiological bases. Inflamm Regen. 2016;36:17.

44. Dardevet D, Rémond D, Peyron MA, Papet I, Savary-Auzeloux I, Mosoni L. Muscle wasting and resistance of muscle anabolism: the "anabolic threshold concept" for adapted nutritional strategies during sarcopenia. ScientificWorldJournal. 2012;2012:269531.

45. Prod'homme M, Rieu I, Balage M, Dardevet D, Grizard J. Insulin and amino acids both strongly participate to the regulation of protein metabolism. Curr Opin Clin Nutr Metab Care. 2004;7(1):71-77.

46. Dardevet D, Sornet C, Balage M, Grizard J. Stimulation of in vitro rat muscle protein synthesis by leucine decreases with age. J Nutr. 2000; 130(11):2630-2635.

47. Liguori I, Russo G, Aran L, et al. Oxidative stress, aging and diseases. Status of the art. Clin Interv Aging. In press 2018.

48. De la Fuente M, Miquel J. An update of the oxidation-inflammation theory of aging: the involvement of the immune system in oxi-inflammaging. Curr Pharm Des. 2009;15(26):3003-3026.

49. Bouzid MA, Filaire E, McCall A, Fabre C. Radical oxygen species, exercise and aging: an update. Sports Med. 2015;45(9):1245-1261.

50. Gomes MJ, Martinez PF, Pagan LU, et al. Skeletal muscle aging: influence of oxidative stress and physical exercise. Oncotarget. 2017;8(12): 20428-20440.

51. Ferroni P, Della-Morte D, Palmirotta R, et al. Platinum-based compounds and risk for cardiovascular toxicity in the elderly: role of the antioxidants in chemoprevention. Rejuvenation Res. 2011;14(3):293-308.

52. Meng SJ, Yu LJ. Oxidative stress, molecular inflammation and sarcopenia. Int J Mol Sci. 2010;11(4):1509-1526.

53. Southgate RJ, Neill B, Prelovsek O, et al. FOXO1 regulates the expression of 4E-BP1 and inhibits mTOR signaling in mammalian skeletal muscle. J Biol Chem. 2007;282(29):21176-21186.

54. Baumann CW, Kwak D, Liu HM, Thompson LV. Age-induced oxidative stress: how does it influence skeletal muscle quantity and quality? J Appl Physiol (1985). 2016;121(5):1047-1052.

55. Woo J. Sarcopenia. Clin Geriatr Med. 2017;33(3):305-314

56. Landi F, Calvani R, Tosato M, et al. Anorexia of aging: risk factors, consequences, and potential treatments. Nutrients. 2016;8(2):69.

57. Morley JE, Farr SA. Cachexia and neuropeptide Y. Nutrition. 2008; 24(9):815-819.

58. Peterson MD, Rhea MR, Sen A, Gordon PM. Resistance exercise for muscular strength in older adults: a meta-analysis. Ageing Res Rev. 2010;9(3):226-237.

59. Washburn RA, McAuley E, Katula J, Mihalko SL, Boileau RA. The physical activity scale for the elderly (PASE): evidence for validity. J Clin Epidemiol. 1999;52(7):643-651.

60. Curcio F, Liguori I, Cellulare M, et al. PASE (Physical Activity Scale for the Elderly) score is related to sarcopenia in noninstitutionalized older adults. J Geriatr Phys Ther. Epub 2017 Aug 3.

61. Cruz-Jentoft AJ, Baeyens JP, Bauer JM, et al; European Working Group on Sarcopenia in Older People. Sarcopenia: European consensus on definition and diagnosis: report of the European Working Group on Sarcopenia in Older People. Age Ageing. 2010;39(4):412-423.
62. Guralnik JM, Simonsick EM, Ferrucci L, et al. A short physical performance battery assessing lower extremity function: association with self-reported disability and prediction of mortality and nursing home admission. J Gerontol. 1994;49(2):M85-M94.

63. Binkley N, Krueger D, Buehring B. What's in a name revisited: should osteoporosis and sarcopenia be considered components of "dysmobility syndrome?" Osteoporos Int. 2013;24(12):2955-2959.

64. De Rui M, Veronese N, Bolzetta F, et al. Validation of bioelectrical impedance analysis for estimating limb lean mass in free-living Caucasian elderly people. Clin Nutr. 2017;36(2):577-584.

65. Goodpaster BH, Thaete FL, Kelley DE. Composition of skeletal muscle evaluated with computed tomography. Ann N Y Acad Sci. 2000; 904:18-24.

66. Fielding RA, Vellas B, Evans WJ, et al. Sarcopenia: an undiagnosed condition in older adults. Current consensus definition: prevalence, etiology, and consequences. International working group on sarcopenia. J Am Med Dir Assoc. 2011;12(4):249-256.

67. Ticinesi A, Meschi T, Narici MV, Lauretani F, Maggio M. Muscle ultrasound and sarcopenia in older individuals: a clinical perspective. J Am Med Dir Assoc. 2017;18(4):290-300.

68. Harris-Love MO, Monfaredi R, Ismail C, Blackman MR, Cleary K. Quantitative ultrasound: measurement considerations for the assessment of muscular dystrophy and sarcopenia. Front Aging Neurosci.2014;6:172.

69. Abe T, Thiebaud RS, Loenneke JP, Loftin M, Fukunaga T. Prevalence of site-specific thigh sarcopenia in Japanese men and women. Age (Dordr). 2014;36(1):417-426.

70. Calvani R, Marini F, Cesari M, et al; SPRINTT consortium. Biomarkers for physical frailty and sarcopenia: state of the science and future developments. J Cachexia Sarcopenia Muscle. 2015;6(4):278-286.

71. Stout JR, Fragala MS, Hoffman JR, et al. C-terminal agrin fragment is inversely related to neuromuscular fatigue in older men. Muscle Nerve. 2015;51(1):132-133.

72. Raschke S, Elsen M, Gassenhuber $\mathrm{H}$, et al. Evidence against a beneficial effect of irisin in humans. PLoS One. 2013;8(9):e73680.

73. Chen L, Liu B. Relationships between stress granules, oxidative stress, and neurodegenerative diseases. Oxid Med Cell Longev. 2017; 2017:1809592.

74. Bloch SA, Lee JY, Syburra T, et al. Increased expression of GDF-15 may mediate ICU-acquired weakness by down-regulating muscle microRNAs. Thorax. 2015;70(3):219-228.

75. Massagué J, Seoane J, Wotton D. Smad transcription factors. Genes Dev. 2005;19(23):2783-2810.

76. Sartori R, Gregorevic P, Sandri M. TGF $\beta$ and BMP signaling in skeletal muscle: potential significance for muscle-related disease. Trends Endocrinol Metab. 2014;25(9):464-471.

77. Lee SJ. Quadrupling muscle mass in mice by targeting TGF-beta signaling pathways. PLoS One. 2007;2(8):e789.

78. Pedersen BK. Muscle as a secretory organ. Compr Physiol. 2013;3(3): $1337-1362$.

79. Nedergaard A, Karsdal MA, Sun S, Henriksen K. Serological muscle loss biomarkers: an overview of current concepts and future possibilities. J Cachexia Sarcopenia Muscle. 2013;4(1):1-17.

80. Bhasin S, He EJ, Kawakubo M, et al. N-terminal propeptide of type III procollagen as a biomarker of anabolic response to recombinant human $\mathrm{GH}$ and testosterone. J Clin Endocrinol Metab. 2009;94(11):4224-4233.

81. Watanabe S, Sato K, Hasegawa N, et al. Serum C1q as a novel biomarker of sarcopenia in older adults. FASEB J. 2015;29(3):1003-1010.

82. Penninx BW, Pahor M, Cesari M, et al. Anemia is associated with disability and decreased physical performance and muscle strength in the elderly. J Am Geriatr Soc. 2004;52(5):719-724.

83. Schalk BW, Deeg DJ, Penninx BW, Bouter LM, Visser M. Serum albumin and muscle strength: a longitudinal study in older men and women. J Am Geriatr Soc. 2005;53(8):1331-1338.

84. Lauretani F, Semba RD, Bandinelli S, Ray AL, Guralnik JM, Ferrucci L. Association of low plasma selenium concentrations with poor muscle strength in older community-dwelling adults: the InCHIANTI Study. Am J Clin Nutr. 2007;86(2):347-352. 
85. Fuentes T, Ara I, Guadalupe-Grau A, et al. Leptin receptor $170 \mathrm{kDa}$ (OB-R170) protein expression is reduced in obese human skeletal muscle: a potential mechanism of leptin resistance. Exp Physiol. 2010; 95(1):160-171.

86. Dominguez LJ, Barbagallo M, Lauretani F, et al. Magnesium and muscle performance in older persons: the InCHIANTI study. Am J Clin Nutr. 2006;84(2):419-426.

87. Visser M, Deeg DJ, Lips P; Longitudinal Aging Study Amsterdam. Low vitamin D and high parathyroid hormone levels as determinants of loss of muscle strength and muscle mass (sarcopenia): the Longitudinal Aging Study Amsterdam. J Clin Endocrinol Metab. 2003;88(12):5766-5772.

88. Liguori I, Curcio F, Russo G, et al. Risk of malnutrition evaluated by mini nutritional assessment and sarcopenia in noninstitutionalized elderly people. Nutr Clin Pract. Epub 2018 Feb 13.

89. Sell H, Habich C, Eckel J. Adaptive immunity in obesity and insulin resistance. Nat Rev Endocrinol. 2012;8(12):709-716.

90. Trendelenburg AU, Meyer A, Jacobi C, Feige JN, Glass DJ. TAK-1/ p38/nNF $\mathrm{KB}$ signaling inhibits myoblast differentiation by increasing levels of Activin A. Skelet Muscle. 2012;2(1):3.

91. Cacciatore F, Della-Morte D, Basile C, et al. Butyryl-cholinesterase is related to muscle mass and strength. A new biomarker to identify elderly subjects at risk of sarcopenia. Biomark Med. 2015;9(7):669-678.

92. Cesari M, Penninx BW, Pahor M, et al. Inflammatory markers and physical performance in older persons: the InCHIANTI study. J Gerontol A Biol Sci Med Sci. 2004;59(3):242-248.

93. Semba RD, Lauretani F, Ferrucci L. Carotenoids as protection against sarcopenia in older adults. Arch Biochem Biophys. 2007;458(2): $141-145$

94. Rockwood K, Mitnitski A. Frailty in relation to the accumulation of deficits. J Gerontol A Biol Sci Med Sci. 2007;62(7):722-727.

95. Fried LP, Tangen CM, Walston J, et al; Cardiovascular Health Study Collaborative Research Group. Frailty in older adults: evidence for a phenotype. J Gerontol A Biol Sci Med Sci. 2001;56(3): M146-M156.

96. Abete P, Basile C, Bulli G, et al. The Italian version of the "frailty index" based on deficits in health: a validation study. Aging Clin Exp Res. 2017;29(5):913-926.

97. Bernabei R, Martone AM, Vetrano DL, Calvani R, Landi F, Marzetti E. Frailty, physical frailty, sarcopenia: a new conceptual model. Stud Health Technol Inform. 2014;203:78-84.

98. Orme JG, Reis J, Herz EJ. Factorial and discriminant validity of the Center for Epidemiological Studies Depression (CES-D) scale. J Clin Psychol. 1986;42(1):28-33.

99. Abete P, Cacciatore F, Ferrara N, et al. Body mass index and preinfarction angina in elderly patients with acute myocardial infarction. Am J Clin Nutr. 2003;78(4):796-801.

100. Cruz-Jentoft AJ, Landi F, Schneider SM, et al. Prevalence of and interventions for sarcopenia in ageing adults: a systematic review. Report of the International Sarcopenia Initiative (EWGSOP and IWGS). Age Ageing. 2014;43(6):748-759.

101. Curcio F, Basile C, Liguori I, et al. Tinetti mobility test is related to muscle mass and strength in non-institutionalized elderly people. Age (Dordr). 2016;38(5-6):525-533.

102. Beaudart C, Zaaria M, Pasleau F, Reginster JY, Bruyère O. Health outcomes of sarcopenia: a systematic review and meta-analysis. PLoS One. 2017;12(1):e0169548.

103. Afilalo J. Conceptual models of frailty: the sarcopenia phenotype. Can J Cardiol. 2016;32(9):1051-1055.

104. Greig CA. Nutritional approaches to the management of sarcopenia. Nutr Bull. 2013;38(3):344-348.

105. Fiatarone MA, Marks EC, Ryan ND, Meredith CN, Lipsitz LA, Evans WJ. High-intensity strength training in nonagenarians. Effects on skeletal muscle. JAMA. 1990;263(22):3029-3034.

106. Fiatarone MA, O’Neill EF, Ryan ND, et al. Exercise training and nutritional supplementation for physical frailty in very elderly people. N Engl J Med. 1994;330(25):1769-1775.
107. Briefel RR, McDowell MA, Alaimo K, et al. Total energy intake of the US population: the third National Health and Nutrition Examination Survey, 1988-1991. Am J Clin Nutr. 1995;62(5 Suppl): 1072S-1080S

108. Sieber CC. Nutritional screening tools - How does the MNA compare? Proceedings of the session held in Chicago May 2-3, 2006 (15 Years of Mini Nutritional Assessment). J Nutr Health Aging. 2006;10(6):488-492; discussion 492-494.

109. Gaffney-Stomberg E, Insogna KL, Rodriguez NR, Kerstetter JE. Increasing dietary protein requirements in elderly people for optimal muscle and bone health. J Am Geriatr Soc. 2009;57(6):1073-1079.

110. Arnal MA, Mosoni L, Boirie Y, et al. Protein pulse feeding improves protein retention in elderly women. Am J Clin Nutr. 1999;69(6): 1202-1208.

111. Morley JE. Pharmacologic options for the treatment of sarcopenia. Calcif Tissue Int. 2016;98(4):319-333.

112. Calvani R, Miccheli A, Landi F, et al. Current nutritional recommendations and novel dietary strategies to manage sarcopenia. J Frailty Aging. 2013;2(1):38-53.

113. Johnson MA, Kimlin MG. Vitamin D, aging, and the 2005 Dietary Guidelines for Americans. Nutr Rev. 2006;64(9):410-421.

114. Bischoff-Ferrari HA, Dawson-Hughes B, Staehelin HB, et al. Fall prevention with supplemental and active forms of vitamin D: a metaanalysis of randomised controlled trials. BMJ. 2009;339:b3692.

115. Morley JE, Argiles JM, Evans WJ, et al; Society for Sarcopenia, Cachexia, and Wasting Disease. Nutritional recommendations for the management of sarcopenia. J Am Med Dir Assoc. 2010;11(6): 391-396.

116. Bjelakovic G, Nikolova D, Gluud LL, Simonetti RG, Gluud C. Mortality in randomized trials of antioxidant supplements for primary and secondary prevention: systematic review and meta-analysis. JAMA. 2007;297(8):842-857.

117. Wilson GJ, Wilson JM, Manninen AH. Effects of beta-hydroxy-betamethylbutyrate (HMB) on exercise performance and body composition across varying levels of age, sex, and training experience: a review. Nutr Metab (Lond). 2008;5:1.

118. Robinson SM, Jameson KA, Batelaan SF, et al. Diet and its relationship with grip strength in community-dwelling older men and women: the Hertfordshire cohort study. J Am Geriatr Soc. 2008;56(1):84-90.

119. Smith GI, Atherton P, Reeds DN, et al. Omega-3 polyunsaturated fatty acids augment the muscle protein anabolic response to hyperinsulinaemia-hyperaminoacidaemia in healthy young and middleaged men and women. Clin Sci (Lond). 2011;121(6):267-278.

120. Marzetti E, Lawler JM, Hiona A, Manini T, Seo AY, Leeuwenburgh C. Modulation of age-induced apoptotic signaling and cellular remodeling by exercise and calorie restriction in skeletal muscle. Free Radic Biol Med. 2008;44(2):160-168.

121. Landi F, Zuccalà G, Gambassi G, et al. Body mass index and mortality among older people living in the community. J Am Geriatr Soc. 1999;47(9):1072-1076.

122. Mercken EM, Carboneau BA, Krzysik-Walker SM, de Cabo R. Of mice and men: the benefits of caloric restriction, exercise, and mimetics. Ageing Res Rev. 2012;11(3):390-398.

123. Ley RE, Peterson DA, Gordon JI. Ecological and evolutionary forces shaping microbial diversity in the human intestine. Cell. 2006; 124(4):837-848.

124. Ticinesi A, Lauretani F, Milani C, et al. Aging gut microbiota at the cross-road between nutrition, physical frailty, and sarcopenia: is there a gut-muscle axis? Nutrients. 2017;9(12). pii: E1303.

125. Buigues C, Fernández-Garrido J, Pruimboom L, et al. Effect of a prebiotic formulation on frailty syndrome: a randomized, double-blind clinical trial. Int J Mol Sci. 2016;17(6). pii: E932.

126. Borst SE, Mulligan T. Testosterone replacement therapy for older men. Clin Interv Aging. 2007;2(4):561-566.

127. Ferrando AA, Sheffield-Moore M, Paddon-Jones D, Wolfe RR, Urban RJ Differential anabolic effects of testosterone and amino acid feeding in older men. J Clin Endocrinol Metab. 2003;88(1):358-362. 
128. Matsumoto AM. Andropause: clinical implications of the decline in serum testosterone levels with aging in men. J Gerontol A Biol Sci Med Sci. 2002;57(2):M76-M99.

129. Morgentaler A, Miner MM, Caliber M, Guay AT, Khera M, Traish AM. Testosterone therapy and cardiovascular risk: advances and controversies. Mayo Clin Proc. 2015;90(2):224-251.

130. Bhasin S, Jasuja R. Selective androgen receptor modulators (SARMs) as function promoting therapies. Curr Opin Clin Nutr Metab Care. 2009; 12(3):232-240.

131. Dalton JT, Barnette KG, Bohl CE, et al. The selective androgen receptor modulator GTx-024 (enobosarm) improves lean body mass and physical function in healthy elderly men and postmenopausal women: results of a double-blind, placebo-controlled phase II trial. J Cachexia Sarcopenia Muscle. 2011;2(3):153-161.

132. Basaria S, Collins L, Dillon EL, et al. The safety, pharmacokinetics, and effects of LGD-4033, a novel nonsteroidal oral, selective androgen receptor modulator, in healthy young men. J Gerontol A Biol Sci Med Sci. 2013;68(1):87-95.

133. Cesari M, Fielding R, Bénichou O, et al. Pharmacological interventions in frailty and sarcopenia: report by the International Conference on Frailty and Sarcopenia Research Task Force. J Frailty Aging. 2015;4(3):114-120.

134. Travison TG, Basaria S, Storer TW, et al. Clinical meaningfulness of the changes in muscle performance and physical function associated with testosterone administration in older men with mobility limitation. J Gerontol A Biol Sci Med Sci. 2011;66(10):1090-1099.

135. Liu CJ, Latham NK. Progressive resistance strength training for improving physical function in older adults. Cochrane Database Syst Rev. 2009;(3):CD002759.

136. Sullivan DH, Carter WJ, Warr WR, Williams LH. Side effects resulting from the use of growth hormone and insulin-like growth factor-I as combined therapy to frail elderly patients. J Gerontol A Biol Sci Med Sci. 1998;53(3):M183-M187.

137. Sumukadas D, Witham MD, Struthers AD, McMurdo MET. Effect of perindopril on physical function in elderly people with functional impairment: a randomized controlled trial. CMAJ. 2007;177(8): 867-874.

138. Band MM, Sumukadas D, Struthers AD, et al. Leucine and ACE inhibitors as therapies for sarcopenia (LACE trial): study protocol for a randomised controlled trial. Trials. 2018;19(1):6.
139. Molfino A, Amabile MI, Rossi Fanelli F, Muscaritoli M. Novel therapeutic options for cachexia and sarcopenia. Expert Opin Biol Ther. 2016;16(10):1239-1244.

140. Naranjo JD, Dziki JL, Badylak SF. Regenerative medicine approaches for age-related muscle loss and sarcopenia: a mini-review. Gerontology. 2017;63(6):580-589.

141. Barberi L, Scicchitano BM, De Rossi M, et al. Age-dependent alteration in muscle regeneration: the critical role of tissue niche. Biogerontology. 2013;14(3):273-292.

142. Lee SJ, McPherron AC. Regulation of myostatin activity and muscle growth. Proc Natl Acad Sci U S A. 2001;98(16):9306-9311.

143. Léger B, Derave W, De Bock K, Hespel P, Russell AP. Human sarcopenia reveals an increase in SOCS-3 and myostatin and a reduced efficiency of Akt phosphorylation. Rejuvenation Res. 2008;11(1): 163B-175B.

144. Macchi C, Molino-Lova R, Polcaro P, et al. Higher circulating levels of uric acid are prospectively associated with better muscle function in older persons. Mech Ageing Dev. 2008;129(9):522-527.

145. Brunelli A, Dimauro I, Sgrò P, et al. Acute exercise modulates BDNF and pro-BDNF protein content in immune cells. Med Sci Sports Exerc. 2012;44(10):1871-1880.

146. Sakuma K, Yamaguchi A. Sarcopenia and age-related endocrine function. Int J Endocrinol. 2012;2012:127362.

147. Sheffield-Moore M, Dillon EL, Randolph KM, et al. Isotopic decay of urinary or plasma 3-methylhistidine as a potential biomarker of pathologic skeletal muscle loss. J Cachexia Sarcopenia Muscle. 2014; 5(1):19-25.

148. Stimpson SA, Leonard MS, Clifton LG, et al. Longitudinal changes in total body creatine pool size and skeletal muscle mass using the D3-creatine dilution method. J Cachexia Sarcopenia Muscle. Epub 2013 June 25.

149. Abreu EL, Cheng AL, Kelly PJ, et al. Skeletal muscle troponin as a novel biomarker to enhance assessment of the impact of strength training on fall prevention in the older adults. Nurs Res. 2014;63(2) 75-82.

150. Meng Y, Wu H, Yang Y, et al. Relationship of anabolic and catabolic biomarkers with muscle strength and physical performance in older adults: a population-based cross-sectional study. BMC Musculoskelet Disord. 2015;16:202
Clinical Interventions in Aging

\section{Publish your work in this journal}

Clinical Interventions in Aging is an international, peer-reviewed journa focusing on evidence-based reports on the value or lack thereof of treatments intended to prevent or delay the onset of maladaptive correlates of aging in human beings. This journal is indexed on PubMed Central, MedLine,

\section{Dovepress}

CAS, Scopus and the Elsevier Bibliographic databases. The manuscript management system is completely online and includes a very quick and fair peer-review system, which is all easy to use. Visit http://www.dovepress. com/testimonials.php to read real quotes from published authors. 